\title{
The Atlas as (Exhibition) Space \\ Herbert Bayer: World Geographic Atlas, 1953.
}

\author{
Magdalena Becker \\ ${ }^{a}$ Assistant Researcher; Academy of Fine Arts Munich; r.magdalena.becker@web.de
}

Keywords: Atlas, Art in Cartography, Map Design, History of Cartography, Modernism

\begin{abstract}
:
In 1948, former Bauhaus designer Herbert Bayer was commissioned by the Container Corporation of America (a cardboard company) to design a world atlas. This atlas was published in 1953 as the "World Geo-Graphic Atlas". My research considers the modernist conception of cartography with an exemplary analysis of this atlas. The atlas oscillates between artwork and cartographic document and can be stylistically located between Bauhaus and American commercial graphics. After presenting the context of the atlas' creation and its classification with particular reference to its function as a promotional gift the atlas is linked to the exhibition "Airways to Peace". This exhibition opened in 1943 at the Museum of Modern Art, New York and was curated by Monroe Wheeler and designed by Herbert Bayer. Visual, content-related but also methodological similarities with the "World Geographic Atlas" catch the eye. Thus, the exhibition is interpreted as a walk-in atlas and the atlas as an exhibition. These hybridizations of media are further discussed.
\end{abstract}

Unlike Renaissance or Medieval atlases, Modern atlases have rarely been discussed as artefacts of visual culture. Above all, the gain in knowledge of the methodology described should be emphasised. The combination of art and cultural history, critical cartography, postcolonial theory and curatorial practice provides new approaches to the study of atlases. The interpretation of an atlas as an exhibition opens up possibilities in the investigation of the spatial concepts expressed.

In addition to this media-theoretical investigation my research examines the world view implicit in the "World GeoGraphic Atlas". This world view is differentiated into categories of time, space and ideological concepts (cultural as well as political and economic). The focus lies on the epistemic alterations in the perception of space as expressed in the atlas. The world seems to have become increasingly "smaller" since the 1940s. The notion of the shrinkage of the world was further reinforced by the geopolitical situation after the Second World War. The efforts of the USA in dominating and shaping the world view that was to determine the post-war discourse is discussed. These tendencies of Americanization are to be critically questioned. As a document of social and cultural history, the atlas is also interpreted as a manifestation of the post-war debate on humanism. On the one hand, the question of how these fields of discourse are constructed and reflected in the atlas will be examined. On the other hand, it will be discussed how these in turn help to determine the artistic appearance of the atlas. 

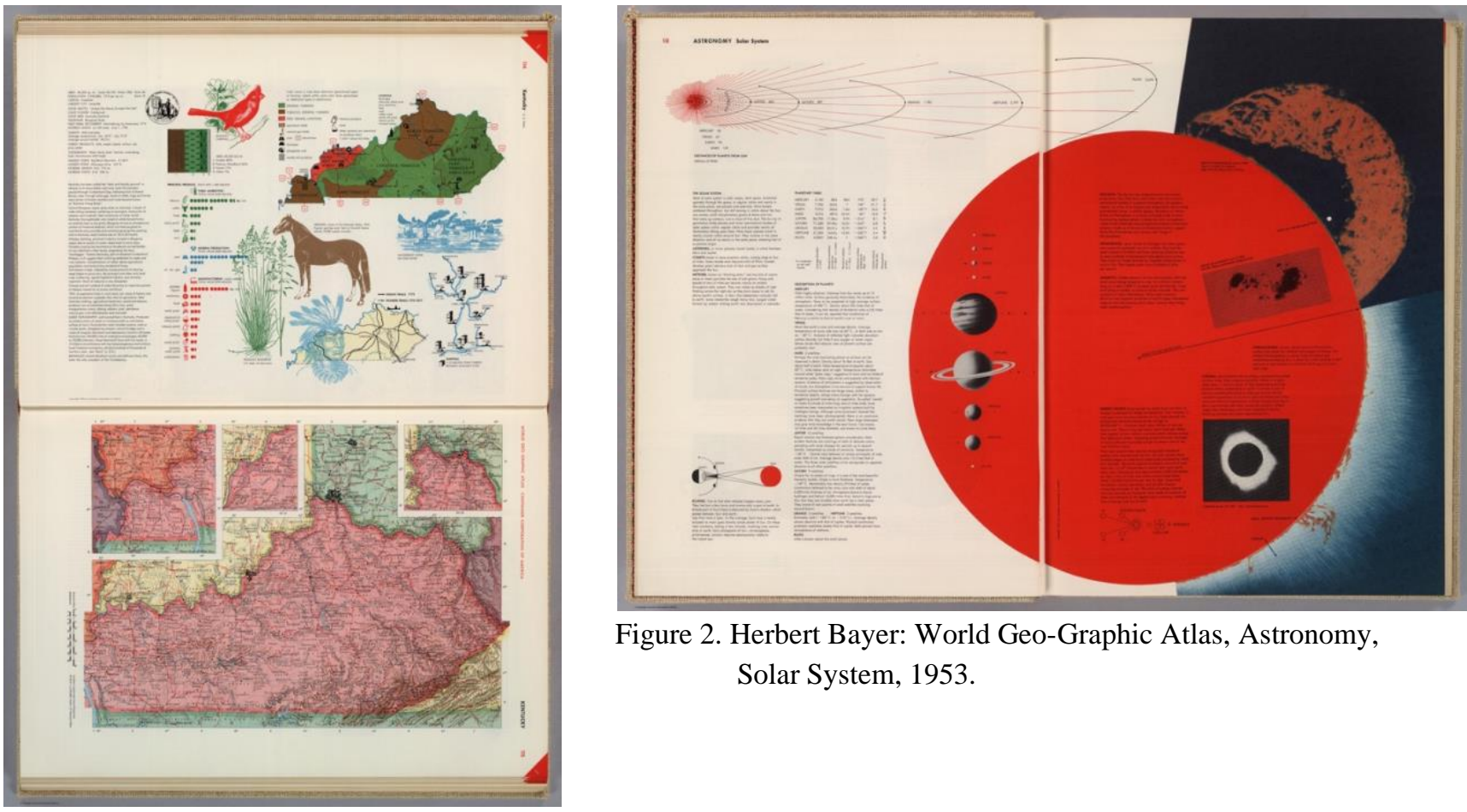

Figure 2. Herbert Bayer: World Geo-Graphic Atlas, Astronomy, Solar System, 1953.

Figure 1. Herbert Bayer: World Geo-Graphic Atlas, Kentucky, 1953.

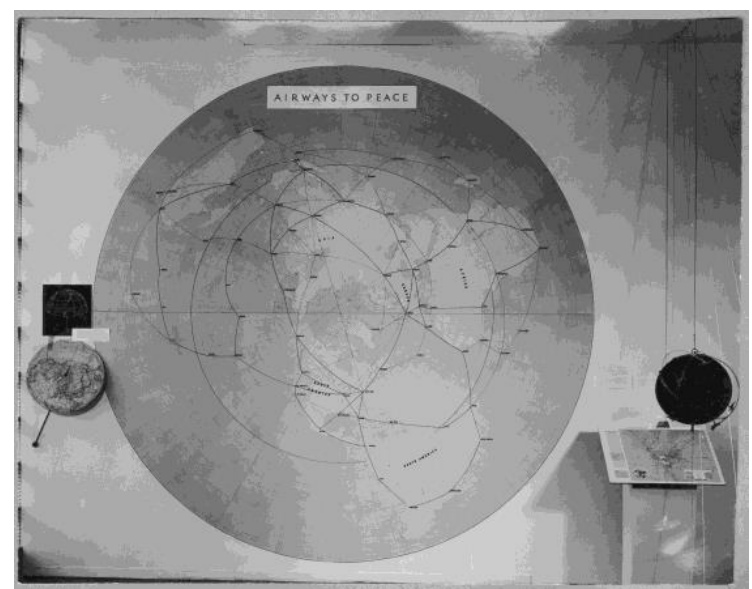

Figure 3. Installation View, Airways to Peace, 1943.

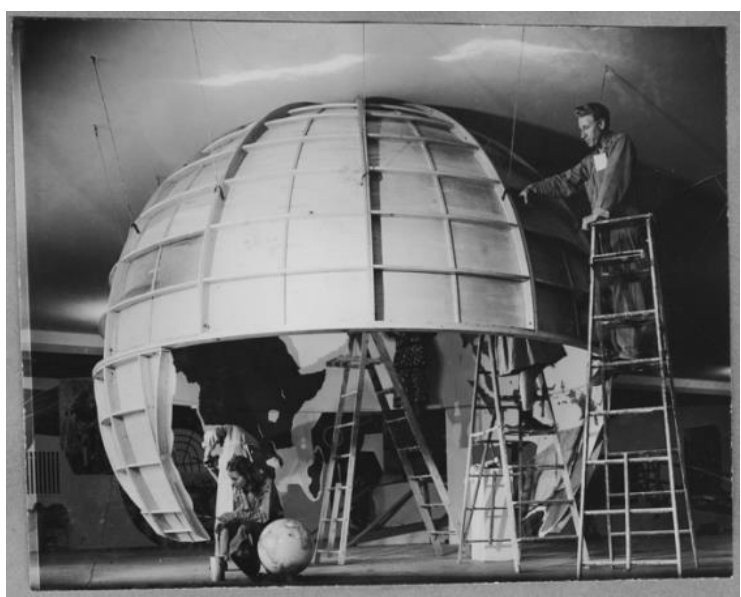

Figure 5. Installation View, Airways to Peace, 1943.

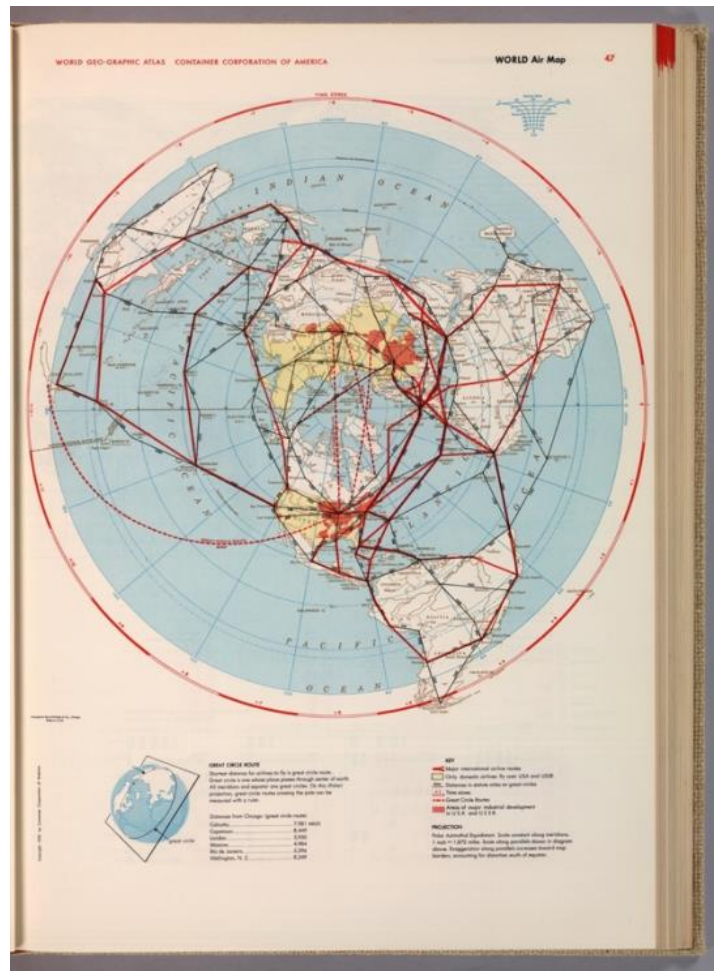

Figure 4. Herbert Bayer: World Geo-Graphic Atlas, World Air Map, 1953. 